\title{
Bordando a luta: O Coletivo de Mulheres do Movimento dos Atingidos por Barragens e as oficinas de Arpilleras como estratégia de mobilização social`.
}

\section{Embroindering the figth: The Women's Collective of the Hit by Dams Movement and workshops of arpilleras with strategy of social mobilization.}

\author{
Monise Vieira Busquets*
}

Resumo: Esse artigo estuda o percurso de mobilização social empenhado na luta pela dignidade humana em contextos de construção de hidrelétricas no Brasil, capitaneado pelo Coletivo de Mulheres, do Movimento dos Atingidos por Barragens (MAB), através da técnica de bordado conhecida como arpillera. As arpilleras ficaram mundialmente conhecidas por denunciarem os contornos de crueldade da Ditadura Militar de Augusto Pinochet (1973-1992). No Brasil, essa técnica de bordado serve como suporte para que mulheres do Coletivo de Mulheres do MAB, bordem as violações dos direitos humanos a que estão sujeitas, o projeto recebeu o nome de "Arpilleras, Bordando a Resistência". A análise aqui contida é uma reflexão elaborada a partir de entrevistas com as militantes e idealizadoras do projeto "Arpilleras, Bordando a Resistência" e fruto da observação participante realizada na Oficina de Arpilleras, durante a exposição "Arpilleras Amazônicas: costurando a luta por direitos”, ocorrida em Belém - PA, em 2016.

Palavras-Chave: Mobilização Social, Movimento dos Atingidos por Barragem, Coletivo de Mulheres, Arpilleras.

\begin{abstract}
This article studies the path of social mobilization committed to the struggle for human dignity in the context of construction of hydroelectric dams in Brazil, led by the Women's Collective of the Hit by Dams Movement (MAB), through the embroidery technique known as arpillera. The arpilleras became known worldwide for denouncing the contours of cruelty of the Military Dictatorship of Augusto Pinochet (1973-1992). In Brazil, this embroidery technique serves as a support for women from the MAB Women's

\footnotetext{
- Esse artigo não teria sido possível sem a colaboração ativa do Coletivo de Mulheres do MAB, especialmente pela disponibilidade de Esther Vital, Tchena Mazo, Cleidiane Vieira, Gizely Moura e Edizângela Barros na concessão das entrevistas aqui contidas.

* Jornalista, Doutora em Ciências do Ambiente. Pesquisa ainda temas como cultura e meio ambiente, subalternidade, a luta pela dignidade humana empreendida por movimentos sociais, tendo como ponto focal de sua carreira acadêmica as formas de violência relegada aos corpos subalternos em territórios coloniais, mais precisamente na Amazônia. Compõe a Rede de Barragens Amazônicas, grupo de trabalho conjunto entre a Universidade Federal do Tocantins, Universidade Federal de Rondônia e a Universidade da Flórida - USA. Atua ainda como Produtora Cultural.
} 
Collective to embroider the human rights violations to which they are subject, the project received the name "Arpilleras, Bordando a Resistência". The analysis contained here is a reflection elaborated from interviews with the activists and creators of the project "Arpilleras, Bordando a Resistência" and the result of the participant observation carried out at the Oficina de Arpilleras, during the exhibition "Arpilleras Amazônica: sewing the fight for rights", which took place in Belém - PA, in 2016.

Keywords: Social Mobilization, Hit by Dams Movement; Women's Collective, Arpilleras.

O Movimento dos Atingidos por Barragens (MAB) desde a década de 1970 tem promovido discussões sobre questão ambiental e o direito das populações ribeirinhas à água, sobretudo, em contextos de construção de hidrelétricas no país todo. Um dos objetivos do MAB é tecer críticas em relação à política energética adotada pelo Brasil e ao padrão de desenvolvimento, articulando a forma como se produzem e distribuem riquezas e a maneira como se apropriam e controlam o recurso ambiental, além de trabalhar ativamente na defesa das populações atingidas pela construção de hidrelétricas.

No tocante à questão de gênero, historicamente as violações sofridas pelas mulheres são acirradas quando da construção de barragens, observa-se o tráfico de mulheres, exploração sexual, mercantilização do corpo feminino, falta de reconhecimento do trabalho informal quando da negociação com as construtoras, quebra dos laços de vizinhança e vulnerabilidade psíquica.

Segundo o Dossiê de Mulheres Atingidas, elaborado pelo MAB (2015), a opressão sofrida pelas mulheres e as violações dos direitos humanos relacionadas aos campos de construção de barragens, estavam na agenda de discussões desde a constituição do movimento, contudo, existia uma participação maior de homens dentro do próprio movimento. Com o avanço nas formações de gênero, foram organizando-se grupos de coordenação mais compostos por mulheres, permitindo assim uma maior inserção das mulheres nas discussões políticas.

A partir da articulação empreendida pelo MAB, o grupo de mulheres em luta organizou-se em um Coletivo de Mulheres, criado durante o I ENCONTRO NACIONAL DAS MULHERES ATINGIDAS, ocorrido de 04 a 07 de abril de 2011. O encontro aconteceu em Brasília - DF e reuniu mais de 500 participantes, incluindo também mulheres indígenas. O Coletivo de Mulheres promoveu uma série de ações com as 
Revista Brasileira de História \& Ciências Sociais - RBHCS

Vol. $12 \mathrm{~N}^{\circ} 23$, Janeiro - Junho de 2020

atingidas para denunciar a violação dos direitos humanos decorrente da implantação das barragens. Entre as ações, destaca-se a elaboração de projetos com fomento internacional para organização do movimento e denúncias de violência contra mulheres em áreas de grandes empreendimentos hidrelétricos, como a UHE Belo Monte.

Dentre as ações propostas, foram organizadas oficinas de arpilleras em 11 estados brasileiros, contando com a participação de aproximadamente 900 mulheres, procuravase debater questões como violência doméstica, prostituição, acesso aos espaços decisórios e outros temas, além de ensinar a técnica de confecção das arpilleras, conforme relatado no Dossiê das Mulheres Atingidas por Barragens, elaborado pelo MAB (2015).

Para sensibilização das mulheres atingidas, o Coletivo do MAB adotou a metodologia das oficinas usadas pela Vicaria da Solidariedade, entidade ligada à Igreja Católica, organizadas no Chile durante a ditadura de Pinochet (1973-1990). Nas oficinas, as mulheres aprendiam a bordar arpilleras para denunciar a violação dos direitos humanos e garantir o sustento da família dos desaparecidos e presos políticos.

Foi durante a ditadura chilena que a costura em arpilleras se tornou popular, símbolo de resistência das mulheres contra as atrocidades do regime de Augusto Pinochet, a técnica tem sua origem numa antiga tradição popular de Isla Negra - Chile.

A palavra arpillera deriva-se do tecido rústico de linhagem, conhecido no Brasil como juta, depois de preparado, recebe bordados com retalhos, fios de lã, sendo alguns confeccionados com figuras em alto relevo, compondo-se assim uma espécie de tapeçaria colorida e tridimensional. A arpillera utiliza sobras de tecidos e de lã para contar histórias que são costuradas sobre o tecido rústico que era reaproveitado pelas mulheres pobres de Santiago como base do bordado, dessa forma, essa técnica de bordado ficou conhecida como "arpillera".

No Brasil, o primeiro contato do MAB com a tapeçaria chilena ocorreu com a exposição Arpilleras da Resistência Política Chilena (2011), no Memorial da Resistência de São Paulo, de 20 de julho a 30 de outubro de 2011 e, no ano seguinte, a mesma exposição, financiada por meio de edital do Ministério da Justiça, o projeto Marcas da Memória percorreu cinco estados brasileiros: RJ, DF, RS, PR e MG.

A partir da exposição Arpilleras da Resistência Política Chilena, o MAB elaborou um projeto de cooperação internacional com a União Europeia com objetivo de diminuir os riscos de violação dos direitos humanos em áreas atingidas por barragens. O projeto do MAB foi gestado durante a mostra "Arpilleras da Resistencia Política Chilena”, a 
partir de um intercâmbio com a curadora chilena da exposição e a coordenadora do projeto do MAB, Esther Vital, pesquisadora têxtil e arpillerista.

Em 2013, O MAB iniciou a sensibilização e a agenda de oficinas para ensinar as mulheres ligadas ao movimento as técnicas da costura e bordado em tecido. O projeto "Arpilleras, bordando a resistência" tinha por finalidade denunciar os impactos socioambientais na vida das mulheres atingidas e a violação dos direitos humanos, além da vulnerabilidade das mulheres em canteiros de obras das grandes usinas hidrelétricas.

\begin{abstract}
A trajetória é bonita, transformadora e feita à mão. Essencialmente voltado para a população feminina, o projeto Arpilleras: bordando a resistência é uma extensão do Movimento dos Atingidos por Barragens (MAB) e utiliza a subjetividade artística como ferramenta para o engajamento político e reivindicação de direitos. (JANUZZI, 2015, p.12)
\end{abstract}

Da mesma forma que as arpilleras chilenas, as arpilleras produzidas por mulheres atingidas são uma forma de empreender a luta pela dignidade humana, através do bordado. Toda arpilleira conta uma história e o conjunto dessas histórias, costuradas por agulha e linha, materializa-se, numa cartografia singular, uma arpillera pode dizer muito sobre a condição das mulheres atingidas pela construção de hidrelétricas.

Essa tapeçaria colorida nasceu de uma tradição campesina do Chile, antes mesmo do golpe de estado chileno, tiveram notoriedade mundial através da obra da cantora, folclorista e artista chilena, Violeta Parra. Antes do golpe, retratavam cenas cotidianas e regionais, como os bailes típicos da "La Cueca" ${ }^{1}$. Violeta Parra divulgou a técnica da arpillera em Paris, expondo no Pavilhão Marsan do Museu de Artes Decorativas do Palácio do Louvre em 1964.

As artes têxteis também possibilitaram dar voz a outros povos oprimidos na América Latina. No Peru, na região andina de Ayacucho, muitas famílias tiveram que deixar suas terras e migrar para os subúrbios de Lima. Suas comunidades foram afetadas pelas diferentes partes envolvidas no conflito, e as suas aldeias foram devastadas durante o período que durou a guerra entre o governo do Peru com o grupo Sendero Luminoso (1980-2000) (GARCIA, 2008).

Embora a costura, o tricô e os bordados fossem parte da tradição do povo peruano de se expressar, tinham como tema a religiosidade e a vida cotidiana e nesse momento as

\footnotetext{
${ }^{1}$ Trata-se de um ritmo musical oriundo da Argentina, Chile e Bolívia, particularmente no Chile a Dança da Cueca foi oficialmente designada como dança nacional em 1979, herança de uma tradição campesina fragmentada pela violência da ditadura militar Chilena (Villarroel; Jara, 2014).
} 
Revista Brasileira de História \& Ciências Sociais - RBHCS

Vol. $12 \mathrm{~N}^{\circ} 23$, Janeiro - Junho de 2020

arpilleras foram utilizadas como forma de resistência a atos repressivos. Para Cusicanqui (2010), o colonialismo do poder tem nas palavras uma função muito peculiar, pois ao contrário de dizerem, elas encobrem, e sob esse signo os povos andinos desenvolveram uma perspectiva própria de resistência. Ainda segundo a mesma autora, as imagens têm a força de construir uma narrativa crítica, são as imagens, mais que as palavras, capazes de captar os sentidos bloqueados pelo silêncio, pela impotência do dizer.

Assim como no Chile, as vítimas foram capazes de encontrar pontos em comum sobre suas experiências, as histórias de deslocamento, perda de entes queridos e a identidade como comunidades rurais, por meio do bordado (GARCIA, 2008).

Assim também as mulheres da África do Sul denunciaram as políticas segregacionistas do Apartheid através do bordado de colchas, costurados a partir de telas. Esses bordados tiveram um papel importante para denunciar e se opor ao Apartheid de forma não violenta, além de canalizar a dor das mulheres que contavam suas histórias através de agulha e linha.

Países da Ásia Central e do sudeste asiático também utilizaram as técnicas têxteis como forma de comunicar suas vivências. No Afeganistão, o ato de tecer expressou as vivências sobre a guerra, desde a invasão russa à luta antiterrorista liderada pelos Estados Unidos, transformou os desenhos afegãos em testemunhos da vida diária, refletindo a violência a que as pessoas estavam submetidas (Ibidem, 2008, p.76).

Nesse sentido, o objetivo desse texto é de refletir sobre o processo de mobilização do Coletivo de Mulheres do MAB através do uso das arpilleras como ferramenta de articulação política das mulheres atingidas em todo o Brasil, refletir sobre os novos espaços sociais ocupados por elas desde o Projeto "Arpilleras, Bordando a Resistência" e também compreender como as oficinas de confecção de bordados se convertem em um espaço de resistência ao modelo energético.

A análise aqui contida é fruto da observação participante realizada na Oficina de Arpilleras, durante a exposição "Arpilleras Amazônicas: costurando a luta por direitos", ocorrida em Belém - PA, em setembro de 2016. Além da observação participante, esse esforço de pesquisa procurou reunir um conjunto de entrevistas com as lideranças e idealizadoras do projeto "Arpilleras, Bordando a Resistência" e também entrevistas com as facilitadoras e militantes do MAB quando da oficina de bordado em Belém - PA.

\footnotetext{
${ }^{2}$ Matéria da página do MAB explica como a exposição foi organizada e apresenta fotografias do evento - <https://www.mabnacional.org.br/noticia/come-exposi-das-arpilleras-no-sescboulevard-em-bel-m>. Acesso em 20 out. 2019.
} 
A escolha da observação participante como percurso metodológico levou em consideração a necessidade de um contato mais estreito entre o pesquisador e o grupo estudado, aspectos de um determinado fenômeno cultural nem sempre estão à superfície, sendo necessário um esforço prolongado, mais detalhado e aprofundado de observação e empatia (VELHO, 2009).

Para Roberto Cardoso de Oliveira (1998), o trabalho da observação participante reside na tríade de olhar, ouvir e escrever. E esse olhar não é um olhar qualquer, mas, antes disso, devidamente sensibilizado pela teoria disponível do grupo estudado, a fim de que nenhum detalhe passe despercebido e os elementos que compõem a realidade local possam cooperar em favor da decodificação dos sentidos sociais. E é sob esse esforço de aproximação que a pesquisa em tela se deu, considerando que a observação participante, o costurar com as mulheres atingidas, a observação mais próxima das formas de conexão entre as bordadeiras, como elas se punham a costurar, o que falavam, como pensavam e sentiam por meio do bordado, poderiam apontar nuances não alcançáveis quando de uma entrevista pontual. Esse período prolongado do pesquisador junto ao campo estudado é onde a busca por evidências simbólicas se dá.

Thompson (1992) reflete que o uso de entrevistas, ou de fontes orais, são de extraordinário valor como testemunho subjetivo, falado, refletindo uma dada realidade social. Desta forma, por meio das entrevistas realizadas, buscou-se compreender como o Coletivo de Mulheres do MAB organiza-se internamente com relação ao projeto das arpilleras.

Através desse conjunto de entrevistas, buscou-se ainda refletir sobre a dimensão da memória, conforme proposto por Michel Pollak, a memória é um elemento constituinte do sentimento de identidade, tanto individual como coletiva, na medida em que "é também um fator extremamente importante do sentimento de continuidade e de coerência de uma pessoa ou de um grupo em sua reconstrução de si” (POLLAK, 1992, p. 204).

\section{Bordando a Resistência: As Arpilleras do MAB}

É com a chamada da União Europeia para o financiamento de projetos de desenvolvimento e direitos humanos voltada ao Brasil que o Coletivo de Mulheres do $\mathrm{MAB}$ conseguiu os recursos necessários para o início do trabalho com as arpilleras. $\mathrm{O}$ 
projeto aprovado visava a realização de oficinas de arpilleras para documentar as violações que as mulheres vinham sofrendo no contexto da construção de hidrelétricas.

De acordo com Esther Vital (2016), sempre houve um entendimento político dentro do Coletivo de realizar encontros de formação com as mulheres, com objetivo de tratar e construir estratégias de superação desses problemas específicos apresentados, mas essas atividades foram sendo deixadas em segundo plano em razão de temas e ações mais urgentes.

É então a partir da aprovação do projeto “Arpilleras, Bordando a Resistência" pela União Europeia que as mulheres se viram com a missão de elaborar coletivamente um projeto político pedagógico que iria nortear as oficinas de arpilleras, seguindo o Plano Geral de Formação e Organização para as Afetadas.

Em setembro de 2013, um grupo de representantes do MAB, composto de 11 mulheres, viajou para a Argentina, onde acontecia a exposição "Retazos testimoniales: arpilleras de Chile y otras latitudes", no Parque da Memória de Buenos Aires, Argentina. Como parte das atividades do núcleo Outras Latitudes, participaram de uma oficina com as arpilleristas chilenas presentes na exposição. No fragmento a seguir podemos intuir a importância desse momento de formação do primeiro grupo de mulheres,

La comprensión adquirida entre las compañeras del potencial emancipador y empoderador de las arpilleras trajo al colectivo la convicción de que las arpilleras podían y debían ser parte central del método de trabajo usado con las mujeres en el próximo periodo (VITAL, 2016, p. 262) ${ }^{3}$.

Seguindo a agenda de ações para a implementação do projeto, foi realizada uma oficina durante o $1^{\circ}$ Encontro Nacional de Mulheres do MAB, ocorrido em abril de 2011 - na cidade de Brasília ${ }^{4}$. Nessa ocasião, participaram cerca de 70 lideranças de comunidades afetadas por barragem, a proposta inicial era que as mulheres aprendessem a técnica de composição têxtil e também que fosse criado um espaço para a elaboração de uma narrativa coletiva, o trecho a seguir explicita essa perspectiva,

En primer lugar, incluir el taller dentro de los propios espacios organizativos del colectivo, hizo que no e valorase como algo "externo", separado. El "crear" arpilleras así no se ve como uma

\footnotetext{
3 Essa citação compõe o livro "La Embarcada Artivista, arterapia y ativismo", editado pela Fundación Museo de la Paz de Gernika e organizado por Carrascosa, Astorka e Idigoras (2016). Como se trata de uma publicação sobre a arte empreendida no ativismo em várias partes do mundo, Esther Vital conta a experiência de implementação da técnina das arpilleras com as mulheres atingidas por barragem do MAB, por isso o trecho citado encontra-se em espanhol.

4 Matéria veiculada no site do MAB à época do evento $<$ http://www.mabnacional.org.br/noticia/come-encontro-nacional-das-mulheres-do-mab>.

Acesso em: 20 out. 2019.
} 
actividad "lúdico-artística", separada de uma dinámica de análisis, discusión y elaboración que se dan dentro de los espacios cotidianos del colectivo, sino como uma herramienta que facilita esta dinámica. Así, las arpilleras son vistas como elemento mediador para el análisis de la realidad y problemática de las mujeres, como uma actividad principalmente "política" (esto traerá también uma serie de dificultades más adelante). En este sentido, tanto en la presentación de las arpilleras al grupo, como en el método de trabajo, nos focalizamos en el componente testimonial das arpilleras (VITAL, 2016, p. 262).

As oficinas de arpilleras, agregadas aos trabalhos já realizados pelo Coletivo de Mulheres, tinham um objetivo muito específico, produzir e recolher uma série de testemunhos têxteis das violações dos direitos humanos sofridos pelas mulheres afetadas por construções de barragens, esses testemunhos coletivos serviriam como fonte documental para a elaboração de um dossiê que trabalhasse detalhadamente as violações ocorridas pelo modelo de implantação de barragens do país.

Esther Vital (2016) revela que a forma de introduzir a técnica das arpilleras no coletivo respeitou as estruturas organizativas do próprio movimento, que visava articular os processos de cima para baixo e de baixo para cima. Desta forma, as 11 mulheres que haviam feito a primeira oficina na Argentina contribuíram na formação de outras 70 mulheres, que por sua vez multiplicaram a técnica levando-a às diversas regiões do país, realizando mais de 100 oficinas em suas comunidades locais.

No ano de 2013, o MAB inicia concretamente o trabalho de confecção dos testemunhos têxteis, por meio de oficinas, a técnica das arpilleras e o debate do feminismo percorrem os mais diferentes espaços sociais. Os temas abordados quando das oficinas dizem respeito a prostituição, violência doméstica, trabalho, acesso a políticas públicas, saúde da mulher, entre outros. Segundo dados do movimento, naquele ano mais de 400 mulheres atingidas confeccionaram por volta de 58 peças em todo o Brasil (MAB, 2015).

As oficinas pensadas pelo MAB seguem o mesmo percurso que as oficinas do Vicaría de la Solidaridad, no Chile, e pode-se inferir que o projeto do MAB, com a coadjuvação de Roberta Bacic e Esther Vital, realizou as primeiras oficinas para formar facilitadoras e expandir a técnica da arpillera às mulheres atingidas das cinco regiões do Brasil. Ao todo foram 12 oficinas com a participação de 465 mulheres (MAB, 2015).

Vital (2016) também discorre sobre a dinâmica das oficinas, segundo ela existia uma preocupação da direção do Coletivo de Mulheres de que a produção de arpilleras não despertasse expectativas econômicas nas mulheres envolvidas, por isso sempre houve o cuidado de explicitar o caráter político da atividade em cada uma das oficinas realizadas 
no Brasil todo.

A dinâmica da oficina inicia-se com uma breve explanação sobre como a técnica foi utilizada como veículo de resistência política no Chile, seguida do debate sobre o modelo energético vigente no país e a construção de hidrelétricas nesse contexto. Depois desse primeiro momento, aborda-se a técnica de feitura de uma arpillera (por meio de uma pequena cartilha elaborada pela coordenação nacional do movimento), seguindo-se à confecção das arpilleras coletivas. $\mathrm{O}$ grupo é sempre dividido entre 4 a 5 mulheres para discussão do tema que será transportado para a arpillera e a posterior confecção da peça. Segundo relato contido no Dossiê das Mulheres Atingidas

A ideia de realizar oficinas de arpilleras com as atingidas objetivou explorar e refletir sobre as potencialidades do uso do testemunho têxtil como forma de resistência. Como a experiência das arpilleristas chilenas, pode-se ajudar no trabalho de documentação e denuncia de direitos humanos que estava sendo desenvolvido com as mulheres atingidas, (MAB, 2015, p. 30).

É um momento de construção da mulher enquanto sujeita de sua história, desde as arpilleras chilenas, a forma de fazer política dessas mulheres não seguiu os padrões dominantes, a maneira de atuar politicamente não condiz com as diretrizes geralmente operadas na política. Segundo avaliação de Vital (2016), a principal contribuição do trabalho com as arpilleras se deu através dos processos de empoderamento das mulheres afetadas.

\section{Arpilleras, empoderamento e a conquista de novos espaços}

O termo empoderamento, de conotação política emancipatória, surge nos anos 1970, ainda no original inglês empowerment. O uso do termo por parte dos grupos feministas tem suas raízes na importância adquirida na ideia de poder através da conscientização política emancipatória que promove a liberação das estruturas que limitam a participação social, intelectual e política (LEÓN, 2000).

O conceito de empoderamento surge como uma estratégia do Movimento das Mulheres do Sul, com vistas a avançar na mudança de suas vidas, gerando, consequentemente, um processo de transformação das estruturas sociais. A partir dessa postura política, o empoderamento é um elemento importante para a conquista das visões alternativas das mulheres, cooperando assim para uma mudança gradativa nas relações sociais (Ibidem, 2000). 
Para Léon (2000), as relações de poder podem significar dominação, mas também desafio e resistência às fontes de poder, no intuito de obter uma maior participação sobre elas. A autora ainda observa que o empoderamento não é algo linear,

El empoderamento no es un proceso lineal con un inicio y un fin definidos de manera igual para las diferentes mujeres o grupos de mujeres. El empoderamiento es diferente para cada individuo o grupo según su vida, contexto e historia, y según la localizacíon de la subordinación en lo personal, familiar, comunitário, nacional, regional y global (LÉON, 2000, [s.p.]).

Dessa maneira, compreende-se empoderamento como um processo que visa a superação da desigualdade de gênero. Busca, antes de mais nada, que as mulheres reconheçam que há uma ideologia que legitima a dominação masculina, desnaturalizando a subordinação promovida pelo modelo patriarcal. Significa a produção de uma mudança de dominação dos homens quanto ao controle do corpo feminino, a sexualidade, a mobilidade e ao abuso físico.

Optou-se pelo uso da categoria na perspectiva organizacional, isto é, com referência as organizações sociais, comunitárias, as quais "oferecem oportunidades para adquirir novas ferramentas, desenvolver um sentido de confiança e de comunidade, e melhorar a vida comunitária" (SILVA E MARTÍNEZ, apud KLEBA e WENDAUSEN, 2009, p. 739) ou, ainda agindo no processo de fortalecimentos dos sujeitos, em espaços de participação popular e democratização política. Empoderamento em processos de mobilizações serve para impulsionar comunidades por melhorias de condições de vida; autonomia ou gestão. (KLEBA; WENDAUSEN, 2009, p 735).

Para Roberta Bacic, curadora da exposição Arpilleras da Resistência Política Chilena, colaboradora na formatação das oficinas do MAB, a técnica da arpillera contribui para o empoderamento da mulher.

As mulheres tiveram que se empoderar diante dos problemas que as afligiam e atuaram com as ferramentas que tinham ao seu alcance, neste caso a costura. As oficinas de arpilleras, apoiadas pela Vicaria de Solidaridad e outras instituições do Chile, geraram nelas um espaço de socialização, fraternidade, diálogo, ação e reflexão. Estas oficinas também foram uma fonte de trabalho (WEISSMAN, 2013, [s.p]).

A construção de hidrelétricas, de acordo com Cruz e Silva (2010), ocasiona a ruptura das relações sociais e econômicas dos atingidos com o espaço habitado. Esse espaço ganha novos usos e sentidos a partir do momento em que o modo de vida é transformado, os projetos de vida são desfeitos, e os laços afetivos são destruídos. Por 
Revista Brasileira de História \& Ciências Sociais - RBHCS

Vol. $12 \mathrm{~N}^{\circ} 23$, Janeiro - Junho de 2020

essa razão, bordar tornou-se um ato de resistência para as mulheres, o drama começa no canteiro de obras, por isso as arpilleras são costuras de memórias que a barragem rompeu. Esther comenta que as próprias mulheres avaliam que o trabalho com as arpilleras criou um espaço de autorreconhecimento, onde elas puderam compreender e fortalecer uma identidade de afetadas, "las arpilleras ham sido un nuevo language para poder resignificar la propria identidad, las proprias relaciones, la propria experiencia, la propria historia" (VITAL, 2016, p. 265).

Outro aspecto importante no trabalho com as arpilleras diz respeito ao ato de narrar, muitas das mulheres se sentem inseguras e incomodadas com narrativas em público ou ainda não se compreendiam como pessoas que têm seus direitos violados. Desta forma, as arpilleras atuam como um elemento mediador, facilitando o processo de integração enquanto costuram e é nessas rodas de conversa que as mulheres podem trocar experiências, impressões e expressar seus sentimentos por meio do bordado. As arpilleras são uma forma de dizer de outra maneira, implicam em descobrir internamente os efeitos de uma determinada experiência, muitas delas traumáticas, e criar elementos e formas que possam explicitar o que vai no interior.

Através da consolidação dessas narrativas têxteis que o Coletivo de Mulheres engendra um marco significativo na ocupação de novos espaços, o projeto culmina na exposição "Arpilleras, bordando a resistência", realizada no Memorial da América Latina, Salão de Atos Tiradentes, na cidade de São Paulo, em 2015.

O processo que levou à exposição foi todo percorrido de forma coletiva, desde a seleção das peças que entrariam para a mostra até a escolha dos eixos temáticos. Foi durante o Encontro Nacional do Coletivo de Mulheres em 2015 que se organizou o processo de documentação das violações dos direitos humanos recolhidos por meio das arpilleras, na ocasião as 70 mulheres que representam suas comunidades no Coletivo recolheram os bordados realizados até então e debateram o tema mais amplo do Dossiê (VITAL, 2016).

Esse grupo maior foi dividido em seis grupos menores com objetivo de estudar, discutir e agrupar as arpilleras em função dos eixos temáticos que organizavam o dossiê, eram eles: mundo do trabalho, laços comunitários, água e energia, violência e prostituição e acesso a políticas públicas. As arpilleras eram agrupadas em relação ao tipo de violações dos direitos humanos que representavam, respeitando os eixos temáticos explicitados. Desta feita, os grupos elegeram três arpilleras para cada eixo temático, a ideia era que o 
conjunto escolhido pudesse representar de forma multidimensional as violações, a composição estética e a narrativa da peça (Ibidem, 2016).

Depois desse primeiro momento, realizou-se uma outra oficina com a curadora Roberta Bacic, a ideia era que os conceitos de curadoria e questões relativas aos cuidados com as peças pudessem ser trabalhados pelas mulheres do MAB, concomitantemente à montagem da exposição em São Paulo.

Conforme relato de Esther Vital (2016), o Coletivo de Mulheres decidiu realizar uma exposição internacional, por isso foram incluídas na mostra 12 arpilleras da coleção Conflict Textiles, dirigida por Roberta Bacic,

El que estuvesse por detrás una coleción de peso internacional hizo que el equipo del Memorial también se compromietese con el proyecto y se arriesgase a trabajar com otro tipo de actor cultural, dejando hacer y poniendo a disposición sus espacios y recursos y "no poniendo muchas pegas" a la transgresíon que supuso la ocupación, literalmente hablando, del Memorial durante un mes (VITAL, 2016, p. 268).

Durante a exposição foram realizados debates, seminários e rodas de conversa sobre o modelo energético, as violações dos direitos humanos em campos de construção de hidrelétricas e o protagonismo das mulheres como agentes de transformação da realidade. Todas essas atividades contaram com a presença de pesquisadores, autoridades políticas, agentes da sociedade civil, militantes de outros movimentos, organizações de direitos humanos, organizações feministas, entre outros.

Mulheres de todo o Brasil afetadas por barragens vieram de suas comunidades para a culminância do projeto, puderam ver as arpilleras bordadas por elas expostas no Memorial e também trabalharam ativamente em toda a preparação do evento, bem como nas visitas guiadas da exposição. As arpilleristas e militantes se dividiram em pequenos grupos organizados por turnos e faziam explanações a respeito dos bordados contidos na mostra. 


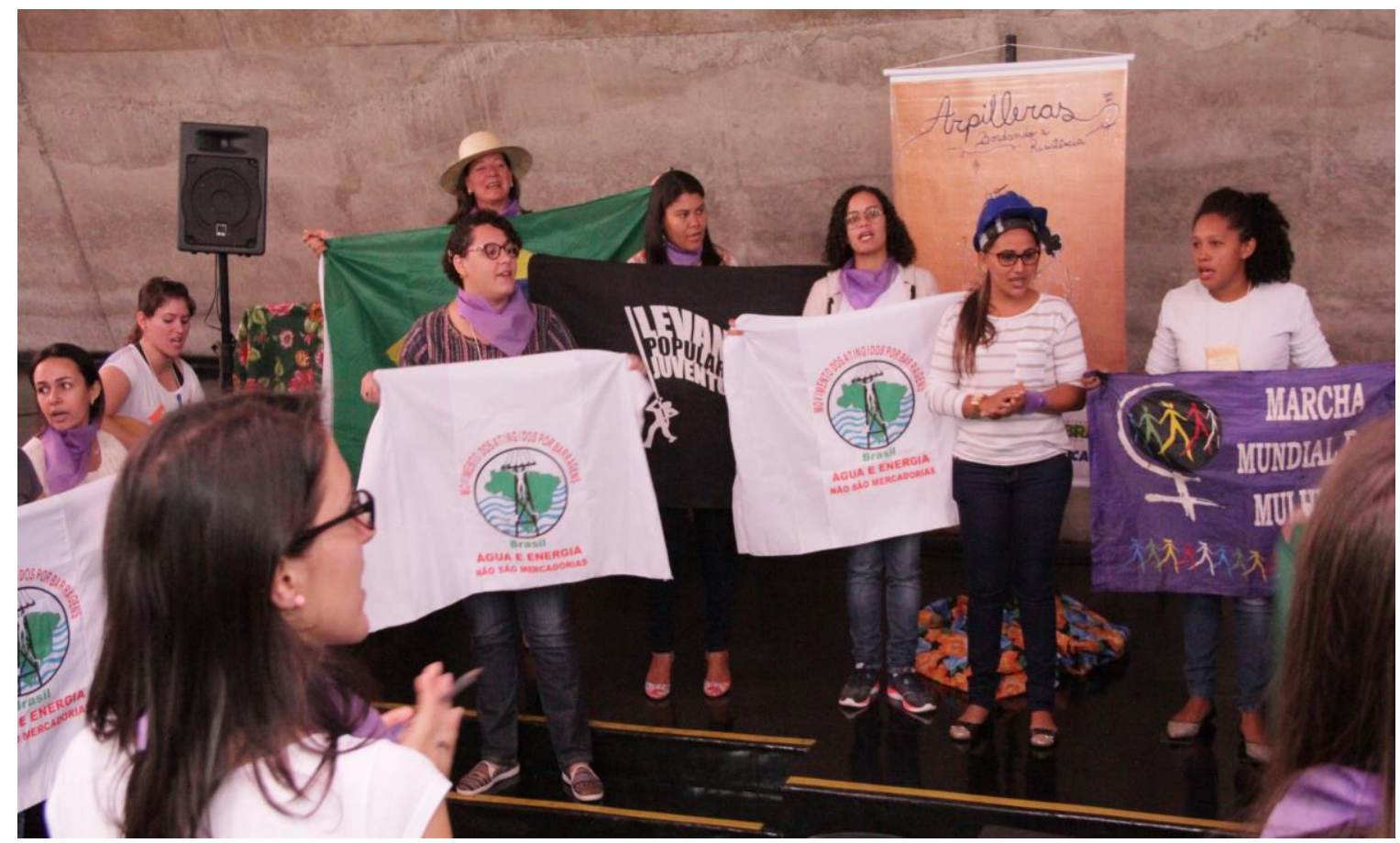

Figura 1 - Momento de reflexão das mulheres na Exposição no Memorial da América Latina em 2015. Foto: Acervo da autora, 2015.

A exposição contou com 24 telas produzidas pelas mulheres atingidas das mais variadas regiões do país, dentre as obras selecionadas, encontravam-se também arpilleras do MAB Nacional, realizadas na Argentina e nos primeiros encontros destinados à explanação da técnica. Era dado o primeiro passo para que as mulheres se reconhecessem como autoras de suas histórias e sujeitas de direitos.

Em entrevista realizada em 22 de maio de 2016, Esther Vital, curadora da exposição e militante do MAB, falou sobre o que significou para as mulheres atingidas ter ocupado o espaço do Memorial da América Latina com as arpilleras,

[...] na questão do empoderamento, eu me lembro assim de chegarem as mulheres e virem as peças delas alí como obra de arte, [...] elas protagonizando isso. Eu me lembro assim, para a Exposição a gente criou uma dinâmica de sempre ter duas mulheres atingidas das regiões lá, durante todos os dias da Exposição para receber as pessoas que vinham ver a Exposição, né?! E no início a gente fazia meio que treinamento com elas para mostrar a Exposição, porque tinha uma parte internacional, então nisso elas chegavam todas tímidas, era super bonito ver como era depois quando elas se colocavam, o protagonismo de explicar para as outras pessoas, sabe?! Nossa a própria ocupação do espaço foi super lindo, super lindo, ver uma mulher chegar assim caladinha, toda humilde, envergonhada, aí ela se colocando, explicando para um grupo toda a Exposição. Isso foi para mim, essa transformação das mulheres no espaço, foi super incrível. E elas se verem ocupando, o simbolismo das mulheres atingidas, a luta delas ocupando o espaço do Memorial. Você chegava lá no Memorial e a Exposição nossa tampava o quadro Tiradentes que estava atrás. Então era o Portinari e o Tiradentes, dois símbolos masculinos, mas era essa a imagem da 
ocupação do espaço simbólico, da gente tirar dois símbolos masculinos de um espaço que tem 50 metros de altura, com as histórias bordadas e a arte, era o símbolo de resistência de Tiradentes dando espaço ao símbolo de resistência das mulheres atingidas, e o do pintor brasileiro internacional pelas artistas bordadeiras da comunidade do artesanato, então eu acho que foi muito legal no nível simbólico. E elas se colocando aí como protagonistas, eu acho que isso deu uma virada, eu me lembro assim, quando nós fizemos a Exposição a gente se viu numa hora um pouco sozinhas, porque era uma coisa que as pessoas não entendiam muito bem como que ia ser... E quando no dia da abertura os homens, olhando aquilo, vendo a repercussão que isso tinha, o simbolismo da gente ocupar um espaço como o Memorial, um espaço nacional, eu acho que foi muito forte ver o protagonismo das mulheres como depois no 8 de março também, eu acho que a gente conseguiu fazer essa viagem de vitimas a protagonistas (Esther Vital, São Paulo SP, entrevistada em 02/05/16).

Através do projeto financiado pela União Europeia, as mulheres iniciaram o processo de feitura das arpilleras, conforme relatado anteriormente, a ideia era promover uma compilação das narrativas contidas nos bordados. Desta forma, o Coletivo de Mulheres consolidou as violações sofridas em uma espécie de relatório, a fim de abrir espaços de discussão nas instituições competentes, o fragmento a seguir demonstra esse objetivo,

A partir de este trabajo de documentación ha sido elaborado un dosier en forma de denuncia $y$ se ha entregado en varios espacios institucionales, proponiendo una serie de recomendaciones para mitigar las violaciones de derechos. Estos esfuerzos han ido de la mano de otros esfuerzos por crear marcos jurídicos que regulen e fiscalicen el tratamiento de las poblaciones afectadas por parte de las empresas (VITAL, 2016, p. 268).

Segundo Sandoval (2004), mulheres que vivem cotidianamente situações opressivas, pouco a pouco adquirem consciência da política patriarcal, a partir de suas próprias experiências cotidianas e desenvolvem, dessa maneira, estratégias de resistência, ainda que não se deem de forma organizada.

Ainda para a autora, um problema no conceito de gênero reside no fato de que está consolidado em uma base material da diferença biológica entre mulheres e homens. Contudo, o que se constrói sobre essa base não é apenas uma feminilidade, mas várias, em relação a uma masculinidade. Dentre as correntes do feminismo da diferença, o ecofeminismo busca entender como se conjuga a divisão dos sexos e a constituição da ordem simbólica, intenta compreender como se dão os processos de legitimação de dominação do homem à mulher e à natureza (LEFF, 2004).

$\mathrm{O}$ ecofeminismo e as reinvidicações de gênero atuam numa política da diferença, 
Revista Brasileira de História \& Ciências Sociais - RBHCS

Vol. $12 \mathrm{~N}^{\circ} 23$, Janeiro - Junho de 2020

não se resumem a uma luta por redistribuição econômica e ecológica, reificando direitos de propriedade e apropriação da natureza a partir da ótica da racionalização, pois que as relações de poder estabelecidas na larga história de dominação da mulher e da natureza não se encerram na divisão de funções e cotas em um mundo coisificado e regulamentado pelo que Leff (2004, p. 8) chama de "sociedade falocêntrica".

Seguindo o feminismo radical, o ecofeminismo vê nas hierarquias sociais do patriarcado a principal causa da destruição da natureza e o domínio da mulher, pois é esse patriarcado que organiza o pensamento, a cultura e as relações de gênero (LEFF, 2004; SHIVA, 1995). Esse mesmo patriarcado regula as relações sociais de gênero e as preferências sexuais - a heterossexualidade como norma -, fazendo, no campo da autoridade e economia, mas também no campo do conhecimento - o que se deve e pode conhecer, quem pode conhecer. Mulheres, indígenas e negros não tinham acesso à cúpula do saber, e mesmo quando desafiavam essa lei, eram marginalizados (JIMÉNEZLUCENA; LUGONES; MIGNOLO; TLOSTANOVA, 2014). Exatamente por este ponto é que a negação da existência epistêmica das mulheres atingidas é ainda mais ampla, profunda e de difícil superação, existe em vários níveis, tanto em relação às questões mais básicas da vida como acesso à comida e serviços de saúde, quanto com relação ao tempo livre para estudar, pensar e fazer participação política.

\section{Oficina de Arpilleras do MAB, uma construção coletiva}

Mesmo depois de findado o fomento da União Europeia, as mulheres do Coletivo continuaram promovendo encontros e discussões sobre o modelo energético e as violações dos direitos das mulheres afetadas utilizando a técnica das arpilleras. Em 2016 o Coletivo de Mulheres organizou uma exposição de arpilleras confeccionadas na região amazônica, a ideia era reunir telas produzidas por mulheres afetadas por empreendimentos na região Norte.

Para a ocasião, foram selecionadas 17 arpilleras, dentre elas haviam telas produzidas por mulheres atingidas por Belo Monte - PA, Tucuruí - PA, Santo Antônio e Jirau - RO, Estreito - MA/TO e arpilleras produzidas por mulheres ameaçadas pelos empreendimentos previstos para Marabá - PA e Tapajós - PA. O evento foi realizado na cidade de Belém - PA e contou com o apoio logístico do Serviço Social do Comércio (SESC). 
A mostra foi dedicada à Nilce de Souza Magalhães, mais conhecida como Nicinha $^{5}$, e reuniu uma série de atividades abertas ao público em geral. Além da exposição, houve exibições de filmes que relatam a luta dos atingidos por barragem, como os documentários "Mãe Amazônia", produzido pela TV Al Jazeera, "Jirau e Santo Antônio" e "Tucuruí, a saga de um povo". Ocorreram também rodas de conversas com as arpilleristas do MAB e uma oficina de bordado que visou ensinar a técnica das arpilleras às mulheres presentes por meio das vivências, experiências e reflexões das próprias participantes.

Em Belém, a mostra expositiva das arpilleras produzidas na região amazônica veio acompanhada de uma série de atividades, entre rodas de conversas e exibições de filmes. Para além disso, o Coletivo de Mulheres do MAB organizou nos últimos dias de exposição uma oficina de arpilleras, que tinha o objetivo de discutir as experiências vividas por mulheres atingidas por barragens. Lá se reuniu um grupo de mulheres de diferentes setores da sociedade, haviam alunas de mestrado da Universidade Federal do Pará, militantes dos movimentos feministas do Estado, interessadas em bordado e mulheres atingidas pela barragem de Belo Monte, além de pessoas que costumavam frequentar as atividades que o SESC realizava na cidade.

A primeira parte da oficina foi toda dedicada a explicitar as origens da técnica e o contexto histórico, as coordenadoras do Coletivo no Pará conduziam as explicações, fizeram um passeio histórico por toda a conjuntura política do Chile e desembocaram nas violações dos direitos humanos sofridas por mulheres do Brasil inteiro com a construção de barragens, foi aí que as participantes puderam entender onde as arpilleras do MAB se inseriam. Foi feito ainda um relato extenso sobre a construção de Belo Monte e das hidrelétricas de Santo Antônio e Jirau, em Rondônia, boa parte das mulheres conhecia os empreendimentos, ou pelo menos Belo Monte, e participavam ativamente das discussões.

5 Militante do MAB assassinada em Rondônia em janeiro de 2016. 


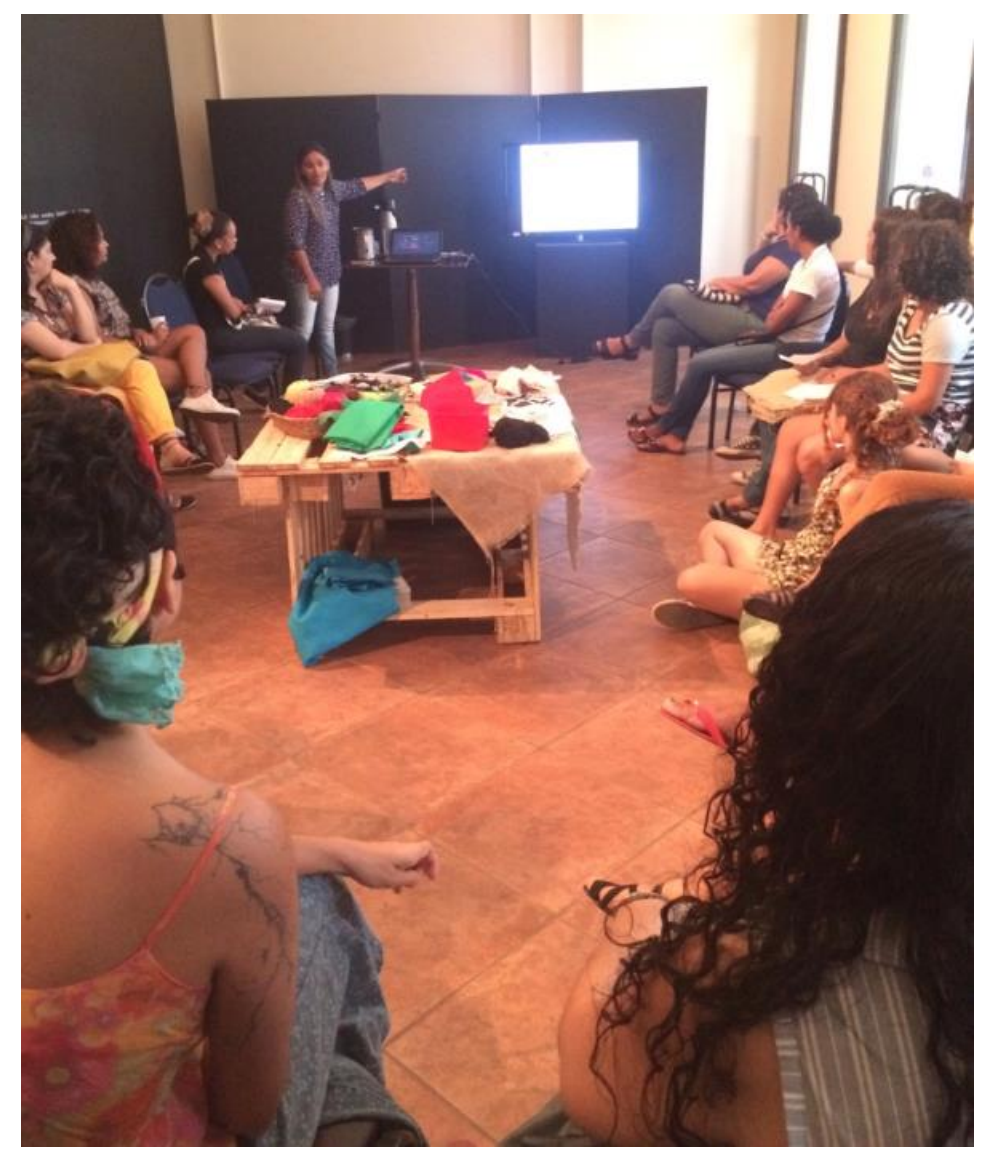

Figura 2 - Oficina de arpilleras da exposição "Arpilleras Amazônicas: Costurando a luta por direitos", realizada em 27 de setembro de 2016. Fotografia-Acervo da autora.

Depois do primeiro momento de explanações, o grupo maior foi dividido em grupos menores de quatro ou cinco mulheres cada, a partir daí as facilitadoras do MAB iriam explicitar como seriam feitas as arpilleras. A primeira instrução dada foi com relação à discussão dos custos sociais e ambientais da construção de barragens no Brasil, a ideia era promover reflexões nesse grupo menor até que fossem formadas as primeiras ideias que comporiam as cenas do bordado, antes do início do bordado é necessário fazer um desenho prévio da arpillera.

Depois de alguns minutos de conversa, um dos grupos decidiu fazer uma arpillera que contasse a história de Belo Monte, os peixes que deixaram de existir, as ilhas que foram tomadas, o trator que atravessava o barco para o outro lado do rio e a ameaça de instalação de uma mineradora na região da Volta Grande do Xingu, Belo Sun. Conforme orientação das facilitadoras, primeiro era necessário um desenho dos elementos que comporiam a cena retratada na arpillera, depois a escolha de tecidos que pudessem melhor representar o que o grupo gostaria de narrar por meio dos bordados.

Algumas das mulheres ficaram responsáveis por fazer o preparo da juta, material que dá suporte ao bordado, outras foram cortando o tecido de acordo com as formas do 
que seria representado, outras se responsabilizavam por fazer as bonequinhas representações de pessoas que compõem as telas - feitas a partir de pedaços de meias de nylon.

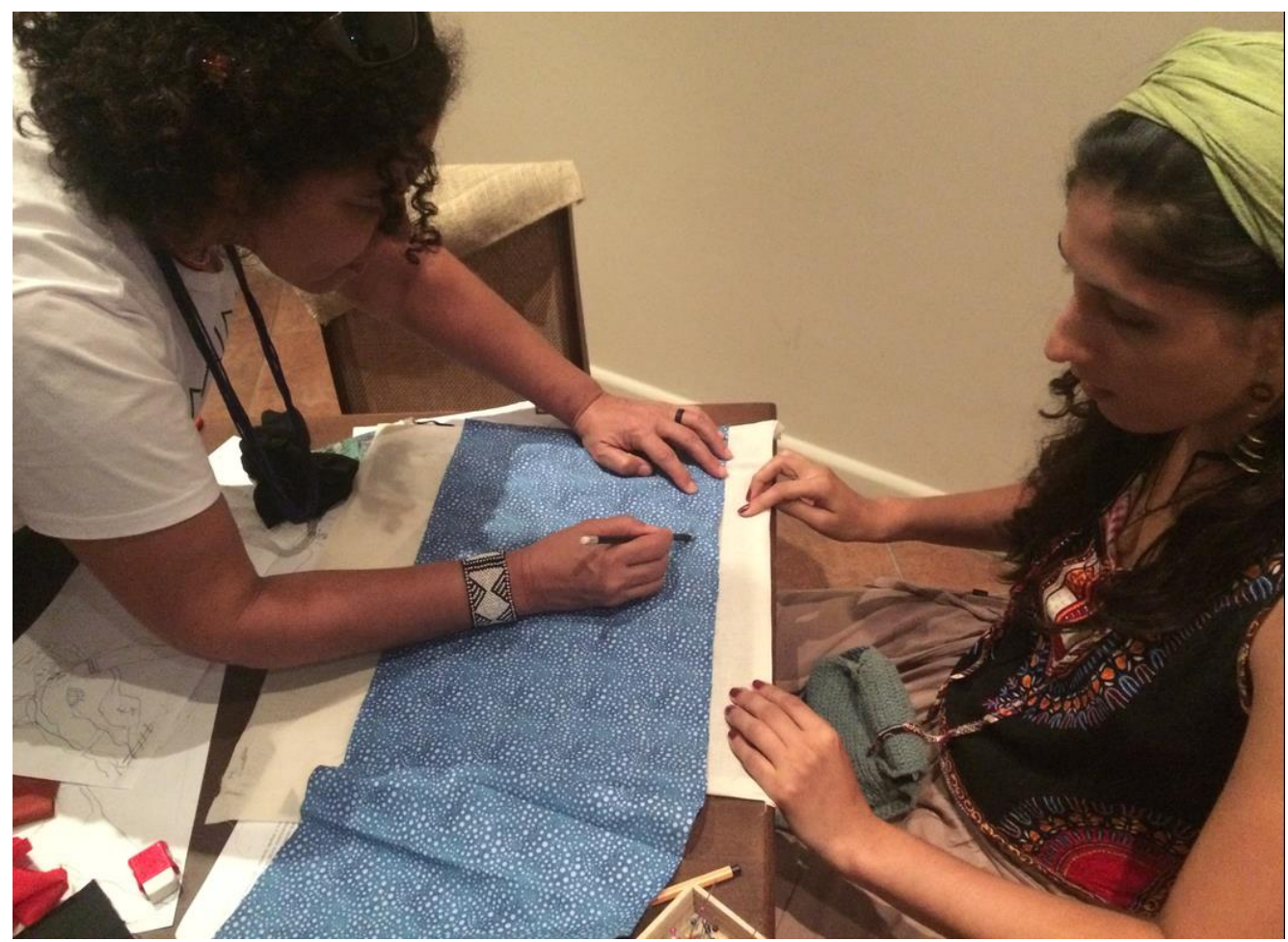

Figura 3 - Processo de bordado coletivo da arpillera "Ouro na Morada dos Deuses", oficina realizada em 27 de setembro de 2016, Belém - PA. Fotografia - Acervo da autora.

As mãos das mulheres eram ágeis, costuravam e falavam sobre como as águas do Xingu eram pulsantes, falavam de como as pessoas se relacionavam com a água do rio, a paisagem primeira, iam tecendo memórias, compondo com tristeza o cenário que a construção da hidrelétrica produziu. A hidrelétrica atingiu os povos tradicionais que viviam ali, ponderavam as companheiras de bordado. Falavam elas, "gente, o rio não corre mais livre", lembrando a todo momento as terras indígenas afetadas, o impacto na vida de plantas, peixes endêmicos e encerraram "a água é dos povos e não de Belo Monte".

Conforme teciam, compondo o cenário ideal para tratar do que as afligia, passaram a discutir também a possível instalação de uma empresa canadense, Belo Sun, que àquela altura já realizava estudos na Volta Grande do Xingu, trecho de vazão reduzida, com vistas à extração de ouro. Essa nova ameaça foi se convertendo no tônus da arpillera que estava sendo bordada. Haviam cerca de 5 outros grupos também bordando e conversando entre si, sempre contando com o apoio e instrução das facilitadoras do 
MAB.

Para a ocasião, as facilitadoras do Coletivo de Mulheres do MAB elaboraram um pequeno passo a passo para o bordado de arpilleras, de posse desse material e das orientações que iam dando aos grupos, era possível criar os elementos a serem fixados na peça, inicialmente as mulheres prendiam cada um desses elementos com alfinetes, até que dispusessem de todo o quadro já preparado, aí então começariam a bordar cada um dos elementos na juta.

Depois de dois dias de oficina, as arpilleras em construção já estavam bem compostas, haviam algumas já finalizadas, por isso as militantes do MAB pediram a todos os grupos que se reunissem novamente para que pudessem discutir o que havia sido feito e qual a impressão que cada uma delas depois da experiência do bordado.

As facilitadoras do MAB também explicitaram que, depois de finalizadas as arpilleras produzidas naquela oficina, era importante que todas as bordadeiras escrevessem uma carta contando a história daquela arpillera, de como haviam pensado sua composição, o que os elementos diziam e o que o bordado significou para suas idealizadoras, ao final poderiam assinar. Também foi solicitado que as arpilleras fossem doadas para o acervo do $\mathrm{MAB}$, pois nenhuma arpillera produzida nas oficinas era destinada à venda, e de posse dessas peças, o MAB faria outras exposições no país inteiro.

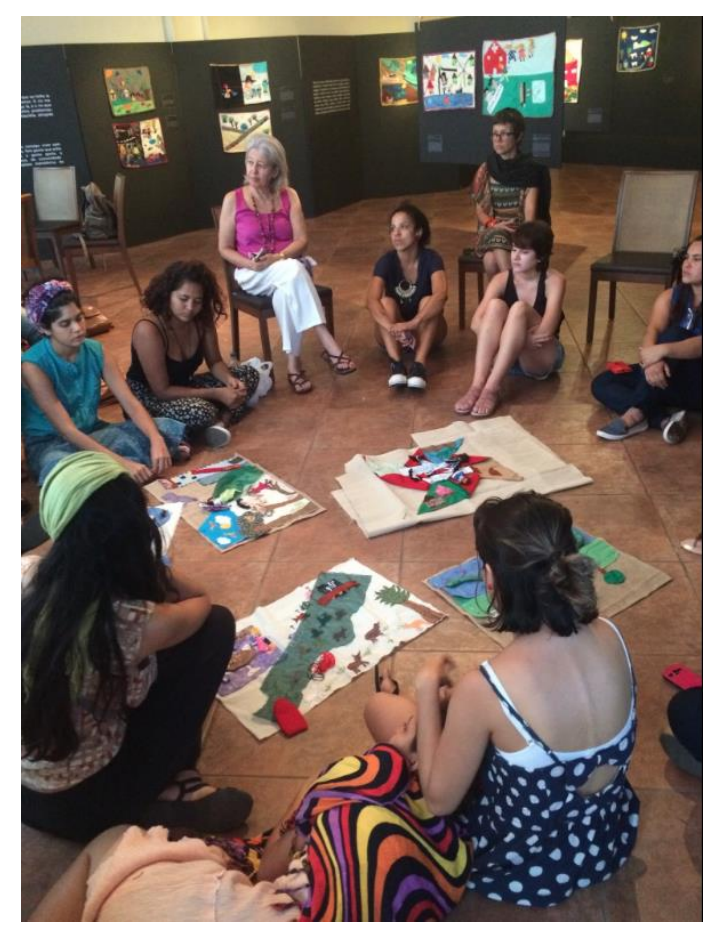

Figura 4 - Grupo reunido com as arpilleras bordadas na oficina da exposição "Arpilleras Amazônicas: Costurando a luta por direitos”, 29 de setembro de 2016, Belém-PA. Fotografia: Acervo da autora. 
No grupo maior podia-se ver a composição de todas as arpilleras produzidas nos grupos menores, como as mulheres haviam pensado a questão da construção de hidrelétricas no Brasil, as mulheres falavam, especialmente, de como a técnica levava à reflexão em profundidade sobre o tema e também estimulava a criação de elementos que pudessem expressar as narrativas discutidas inicialmente, era notável que cada arpillera contava uma história.

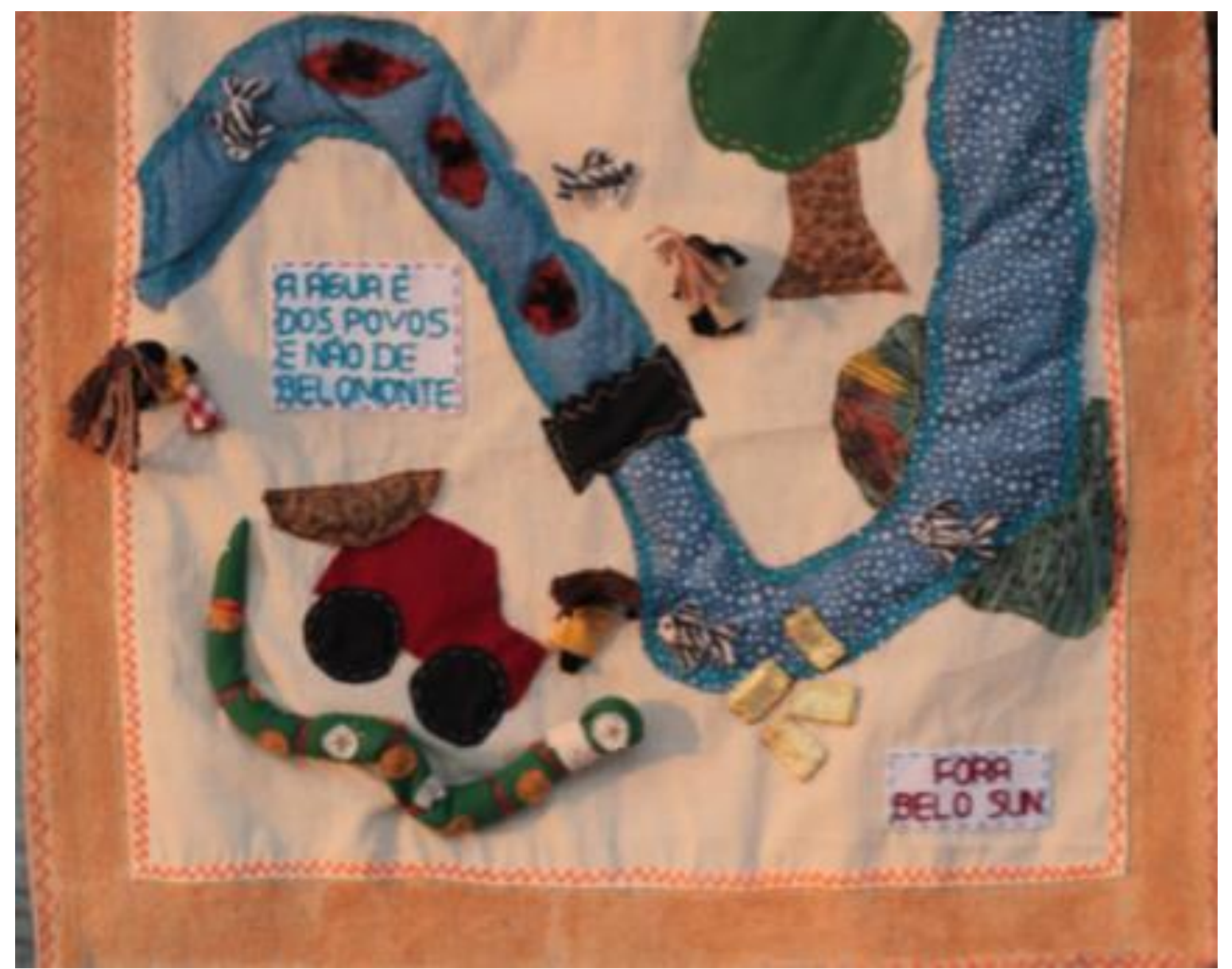

Figura 5 - Arpillera “Ouro na Morada dos Deuses”. Tela bordada por Cynthia Cárdenas, Mayara La Roque, Monica Lizardo, Monise Busquets e Ciléa Malato, acervo do MAB. Oficina de bordado realizada na exposição “Arpilleras Amazônicas: Costurando a luta por direitos”, 29 de setembro de 2016, Belém - PA. Fotografia: Acervo da autora.

Sobre como as oficinas são organizadas pelas facilitadoras do Coletivo de Mulheres, a militante do MAB, Gizely, relata a seguir,

Bom, a gente vem organizando as comunidades para falar do modelo energético para fortalecer a base, para fortalecer e organizar, fazer grupos de base dentro da comunidade e para isso a gente usa da técnica das Arpilleras, o que nos ajuda a chamar as mulheres para vim discutir violações dos direitos humanos, vim discutir o que é seus direitos, 
conhecer mesmo. E quando a gente vai fazer essas oficinas das Arpilleras, trabalha primeiro o debate político, o que é o MAB, o que é esse modelo energético, para que depois a gente possa trabalhar a técnica das Arpilleras trazendo esse debate do que foi feito (Gisely Moura, Belém - PA, entrevistada em 29/09/16).

Outro aspecto que merece ser mencionado com relação ao uso das arpilleras e a realização de oficinas como ferramenta de mobilização social, diz respeito a capilaridade da estratégia de resistência desenvolvida pelas mulheres. Conforme destacado anteriormente, o Coletivo de Mulheres, assim como o próprio MAB, tem uma Coordenação Nacional, se subdividindo em Coordenações Regionais, assim também ocorreu com a realização de oficinas de arpilleras. A Coordenação Geral do Coletivo de Mulheres foi preparando as facilitadoras para que em suas regiões elas pudessem fazer o trabalho de ensinar a técnica do bordado, além de promover os debates sobre o modelo energético vigente, o que são os direitos humanos, que tipos de violação desses direitos os atingidos por barragens estavam sofrendo ou poderiam vir a sofrer. Nesse sentido, Cleidiane Vieira, Coordenadora do Coletivo de Mulheres do MAB no Estado do Pará, relata como o movimento foi se organizando localmente,

O MAB fez um plano de formação a nível nacional com as mulheres, isso ainda no início, não era só falar sobre as Arpilleras, como seria todo debate que nós iriamos fazer em torno do modelo energético e a violação dos direitos das mulheres nesse processo, então a partir daí, desse plano nacional, cada estado deveria fazer os encontros com as mulheres, de acordo com a realidade de cada estado, né?! Aí entra nós, nossa tarefa enquanto mulheres militantes do MAB é fazer esse trabalho aqui na região, então nós tínhamos mais a tarefa de saber o que é a Arpillera, explicar [...] para as mulheres fazerem. Então muitas vezes nós estamos aprendendo a fazer os pontos ainda, mas acima de tudo foi passar o que são as Arpilleras e qual o sentido que nós estamos dando para as Arpilleras (Cleidiane Vieira, Belém - PA, entrevistada em 29/09/16).

Para Cleidiane, a partir da realização de oficinas de arpilleras, as mulheres têm conseguido bordar muitos dos vilipêndios da condição humana que vem sofrendo em suas comunidades, é através das arpilleras que essas mulheres tiveram condições de contar o que acontece nos campos de construção de hidrelétricas. Foi a partir da iniciativa do bordado que o Coletivo de Mulheres do MAB pôde iniciar um processo de sistematização e organização de um dossiê a respeito das violações que os atingidos vêm sofrendo por conta da instalação de grandes projetos desenvolvimentistas em seus territórios. 
Para as mulheres bordadeiras do MAB, o ato de bordar é também um ato político, é por meio do bordado que elas contam histórias de um mundo que já não existe, ou denunciam as misérias causadas na vida delas próprias e dos seus, no contexto do desenvolvimento predatório. O que move a luta contra a investida do capital nos territórios sagrados das populações ribeirinhas e indígenas da Amazônia, é o desejo de que suas vozes sejam respeitadas, de contar elas próprias a história vivida ou desejada (SOARES, 2019).

Ainda conforme Soares (2019), o ato de bordar é em si mesmo a partilha da memória no momento que as mulheres estão bordando, aquecido e reaquecendo a razão uma vez mais por meio da troca de experiências, sentimentos, entendimentos e narrativas, promovidas nas oficinas. E é também produto, quando uma tela nova é finalizada e embebida nas histórias e narrativas que comungam com as perspectivas nascidas no interior da luta. É por meio do bordado que o movimento de mulheres busca levar ao mundo dividido e profundamente marcado pela injustiça, o grito dos excluídos, isso em si mesmo é narrativa materializada.

\section{Considerações Finais}

Considerando as narrativas das bordadeiras do MAB, desde as idealizadoras do projeto, até as mulheres que lutam pela sobrevivência nos mais diferentes lugares do país, observa-se que as arpilleras ocuparam muitos espaços de enunciação na arena pública que, de outra maneira, não teriam ocupado, seja por seu caráter artesanal, seja pela articulação interna do movimento social. O que destaco especialmente aqui é que, por meio de agulha e linha, suportes e materiais relegados à mulher e, portanto, ao universo doméstico, elas foram ao espaço público e falaram de política. Ainda que tenham se travestido de alguns códigos de conduta esperados para esse lócus enunciativo, a esfera pública, o fizeram a partir de seu próprio olhar, o fizeram tendo em conta as dores e histórias vividas e o fizeram sob uma perspectiva que Segato (2016) reconhece como escrever a história pelas mãos femininas.

O caráter anti-patriarcal da luta do Coletivo de Mulheres do MAB reside no fato delas buscarem ser representadas por si mesmas, como sujeitas da própria história e das experiências por elas vividas, as mulheres foram vistas como agentes de sua própria história e não relegadas apenas ao lugar de vítimas. 
Revista Brasileira de História \& Ciências Sociais - RBHCS

Vol. $12 \mathrm{~N}^{\circ} 23$, Janeiro - Junho de 2020

É também notável como a metodologia das arpilleras e, sobretudo, as oficinas de bordado, levaram as mulheres a se reunir, com o objetivo de discutir a construção de hidrelétricas e os direitos humanos, usando o espaço coletivo para imprimir uma luta pela dignidade humana e, sobretudo, a construção de uma mobilização coletiva que denuncia as violações dos direitos humanos e a violência a que estão relegadas em seus territórios de origem.

Ao observar lutas como essa e tantas outras que estão em curso na América Latina, lutas que ressignificam os espaços e as relações de poder segundo a perspectiva de quem luta, de quem reivindica o olhar, tem-se em curso um movimento um tanto maior que o próprio objeto luta, qual seja: a terra, a dignidade humana, tem-se em curso a construção de caminhos alternativos que levem em conta outras epistemologias, contadas a partir das mãos de quem sofre.

\section{Referências}

CUSICANQUI, S. R. Sociología de la imagen: Miradas chìxi desde la história andina. Ciiudad Autónoma de Buenos Aires: Tinta Limón, 2015.

CRUZ, C. B.; SILVA, V. P. Grandes projetos de investimento: a construção de hidrelétricas e a criação de novos territórios. Sociedade \& Natureza, 22(1), 181-190, 2010 .

GARCIA, E. V. The Quilt Project" y “ The Art of Survival Exhibition : International and Irish QuiltS. Instituto de Derechos Humanos Pedro Arrupe. Máster en Acción Internacional Humanitaria. Universidad de Deusto, 2008.

KLEBA, M. E; WENDAUSEN, A. Empoderamento: processo de fortalecimento dos sujeitos nos espaços de participação social e democratização política. Saúde e Sociedade. São Paulo, v.18, n.4, p.733-743, 2009.

JANUZZI, L. Arpilleras: Bordando a resistência. Revista Radis - Comunicação e Saúde. Fundação Osvaldo Cruz. Junho, 2015.

JIMÉNEZ-LUCENA, I;. LUGONES, M.; MIGNOLO, W.; TLOSTANOVA, M. Género y descolonialidad. Buenos Aires: Del Signo, 2014.

LEÓN, M. Empoderamiento: Relaciones de las mujeres com el poder. Estudos Feministas, v. 8, n. 2, p. 191, 2000.

LEFF, E. Ecofeminismo: el género del ambiente. Polis [Em línea], 9 2004. Disponível em: <www.polis.revues.org > . Acesso em: 22, ago. 2017.

MAB. Dossiê de Mulheres Atingidas. São Paulo, 2015. Não publicado.

OLIVEIRA, R. C. O Trabalho do Antropólogo. Brasília: Paralelo 15; São Paulo: 
Editora UNESP, 1998.

POLLAK, M. Memória e Identidade Social: Estudos Históricos. Rio de Janeiro, v. 5, p. 200-2012, 1992.

SANDOVAL, C. Feminismo cyborg y metodología de los oprimidos. In: Otras inapropiables: Feminismos desde las fronteras. Madrid: Traficantes de Sonhos, 2004.

SEGATO, R.L. La Guerra contra las Mujeres. Madrid: Traficante de Sonhos, 2016.

SHIVA, V. Abrazar la Vida. Mujer, ecología y desarollo. Madrid: H. Horas. 1995.

SOARES, M. V. B. Tecendo a luta: memória, violência e violação dos direitos humanos em arpilleras bordadas por mulheres atingidas pela UHE Belo Monte. 2019. 253f. Tese (Doutorado em Ciências do Ambiente) - Universidade Federal do Tocantins, Programa de Pós-Graduação em Ciências do Ambiente, Palmas, 2019.

THOMPSON, P. A Voz do Passado: história oral. Rio de Janeiro: Paz e Terra, 1992.

VELHO, G. Antropologia Urbana: Encontro de tradições e novas perspectivas.

Sociologia. Revista Problemas e Práticas, n.59, pp.11-18, 2009.

VILLARROEL, J. M. P; JARA, M. S. M. Reconstrucción Histórica de la Cueca Sola: Desde el imaginario político y social en Chile (1978 - 1990). (Tesis) Universidad de Artes y Ciencias Sociales. Escuela de Historia y Ciencias Sociales. Santiago, 2014.

VITAL, E. Arpilleras y empoderamiento afectadas por represas, de víctimas a defensoras de derechos humanos. In: CORRASCONA, A; ASTORKA, I. M;

IDIGORAS, M. O. La Embarcada Activista: Arteterapia y activismo. Fundación Museo de la Paz de Guernika. 2016. Disponível em:

$<$ https://issuu.com/gernikagogoratuz/docs/_ndice libro laembarcada artivista $>$.

Acesso em: 05, jul. 2018.

WEIMANN, G. Bordar, ato transgressor? Revista Outras Palavras. 2013 Disponível em: $<$ https://outraspalavras.net/sem-categoria/bordar-ato-transgressor/>. Acesso em: 17 nov. 2016. 